\title{
Prosocial Behavior in Different Situations among Men and Women
}

\author{
Farha Iqbal ${ }^{1}$ \\ Department of Psychology, University of Karachi,Pakistan
}

\begin{abstract}
To explore the influencing situations for prosocial behavior in men and women (both married and unmarried) between the age groups of 20-40 years. For this purpose a sample of 240 participants was presented with 4 different situations: 1) Accident Victim 2) Neighbor fighting 3) Molestation and 4) Shoplifting, then the participants were to decide from the options provided as to how they would intervene with the situation. Out of the 240 participants, 120 were males \& 120 females, of which 60 were married \& 60 were not married. Chi square and t-test were used for calculation. Following results were shown: more people would help indirectly than directly \& only few would not help in all the situations. It was also indicated that helping behavior would differ from situation to situation. Whereas there was no difference found between men and women (married or unmarried) that would help directly or indirectly.
\end{abstract}

Key words: Prosocial Behavior, Married, Unmarried, four situations, directly and indirectly helping.

\section{Introduction}

"Prosocial behavior" is defined as a voluntary behavior performed with the intention of benefiting another person or group of person (Stang and Wrightsman, 1981) some psychologist prefers to use the term "helping behavior". Helping behaviour in humans ranges from generous selfless acts to ignoring real needs. The American Red Cross received \$2.4 billion to help victims of Hurricane Katrina (Strom, 2006). Yet, in 1964 the infamous murder of Kitty Genovese shook researchers and citizens alike when up to thirty-eight neighbours witnessed the attack and did nothing (Kassin, Fein, \& Markus, 2008). As a result, social psychologists became more interested and concerned with the factors associated with helping behaviour.

Several factors are involved in whether or not someone chooses to help another individual in different situations. Researchers majorly suggest three factors: Firstly individuals are less likely to help when others are around due to a "diffusion of responsibility" (Darley \& Latané, 1968). If several other people are present, the obligation to help and the possible costs of failing to help are shared. Not just the number but feelings of personal responsibility are lessened. Secondly ambiguity in the interpretation of the situation, potential helper is sometimes uncertain whether a particular situation is actually an emergency. The behavior of other bystanders can influence how we define a situation and react to it. Latanè \& Darley (1970) did a study where smoke came into room. When participant were alone, 75\% reported to researcher within 4 minutes. One participant with 2 confederates who ignored smoke, only 10\% reported smoke. And lastly if we know that other people are watching, we may get "stage fright." This happens more so if the situation is ambiguous or the required action is not clear Cramer et.al (1988) found that when an accident was staged in front of two people, occurred in front of a person who was alone, unqualified college students and qualified nurses were equally likely to offer assistance.

The cost-reward analysis of helping (Piliavin et al. 1982) assumed an economic view of human behavior-people are motivated to maximize their rewards and to minimize their costs. From this perspective, people are relatively rational and primarily concerned about their self-interest. In an emergency, potential helpers analyze the circumstances, weigh the probable costs and rewards of alternative courses of action, and then arrive at a decision that will result in the best personal outcome for them. Research findings are consistent with the central tenet of the cost-reward approach. Situational factors that make bystander interventions more likely to occur include those that decrease the net costs of helping (e.g., by framing helping as an opportunity for personal development; Perlow \& Weeks 2002), increase potential rewards of helping (e.g., by enhancing mood; Gueguen \& De Gail 2003), or increase the costs of not helping (e.g., by inducing guilt or shame for inaction) (Dovidio et al. 1991).

Prosocial behavior varies greatly across societies and culture (Cohen, 1972). Cultures greatly affect the extent to which humans of different societies act. A culture establishes unwritten guidelines for a society to follow, concerning values and morals. A good way to measure altruism in a society is to study religion. Religion plays a very important role in establishing values and morals all over the world. These values and morals often set the standards that people follow for things like altruism. The religious texts of all major religions have one commonality: they all explicitly encourage pro-social behavior among their followers (Batson et. Al, 1993). For 
example, in Christianity, one of the passages promoting helping behavior is the story of the Good Samaritan, which emphasizes the need for altruism towards others to be practiced in the daily life of its followers. Similarly, Islamic teachings emphasize acts of charity and see helping others in need as a necessity

Evidence suggests that environmental factors may be manipulated to influence an individual's mood. Participants subjected to conditions designed to induce positive moods were more likely to engage in helping behavior (Guéguen \& De Gail, 2003). For instance, people who have been the recipients of smiles, increased eye contact, or touch are more likely to help than others (Goldman \& Fordyce, 1983; Guéguen \&De Gail, 2003). Studies have also ascertained that helping behavior increases on sunny days, cooler days in summer, and warmer days in winter (Cunningham, 1979). Baron (1997) demonstrated that in the presence of pleasant smells, customers in a shopping mall were more likely to either retrieve a pen or provide change for a dollar for another customer.

Individuals are more likely to help someone of the same race (Kunstman \& Plant, 2008) and when the situation reflects culturally determined social roles. For example, men have been found to help women more often than men, demonstrating behavior consistent with social roles (Karakashian et al., 2006; Levine \& Crowther, 2008).In western societies, gender has been shown to be an important factor in helping behavior, although results have been contradictory. Men have been found to be more likely to help than women (Feinman, 1978), women have been found to be more likely to help than men (Bihm, Gaudet, \& Sale, 1979), and still other studies show no difference between the two (Benson, Karabenick, $\boldsymbol{\&}$ Lemer, 1976; Boice $\boldsymbol{\&}$ Goldman, 1981). The gender of the person being helped is an important factor in helping behavior because men and women may be more willing to help a person of the opposite sex (Basow \& Crawley, 1982; Begin, 1978); furthermore, the attractiveness of the person being helped can influence the willingness to help, especially for male helper (Benson, et al., 1976; Harris \& Bays, 1973).

\section{A MODEL OF FACTORS THAT FOSTER OR INHABITS ALTURISTIC OR HELPING BAHVIOR.}

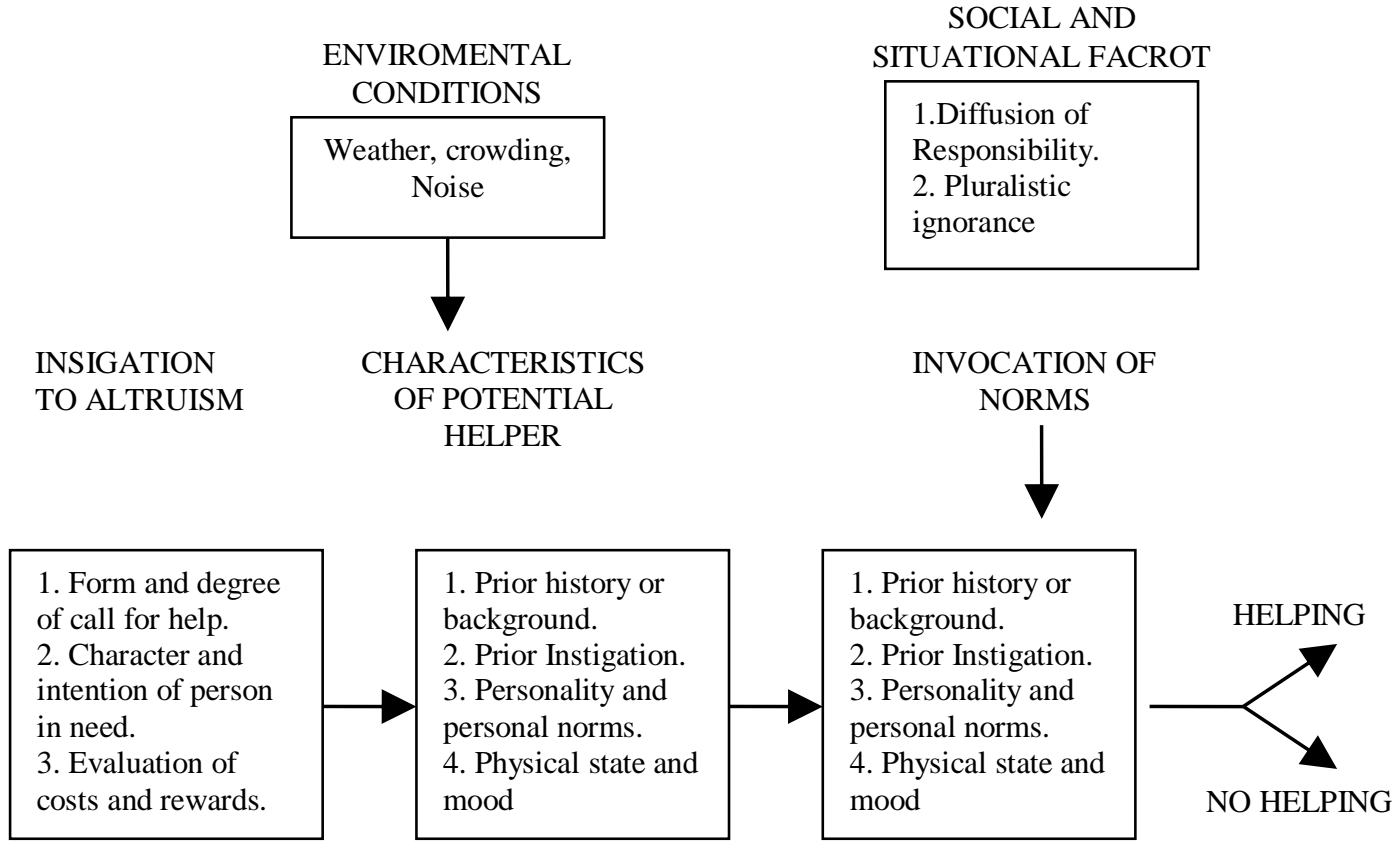

Our study was conducted to explore the different influencing situations for helping behavior in men and women Previous research has shown the nature of the situation that have an effect on helping behavior. In order to explore the difference of helping behavior directly or indirectly in men and women (married or unmarried), we used four situations, assessed participants' reaction, and measured helping behavior. We hypothesized that:

- More people will show helping behavior indirectly as compared to directly and only few will help in all the four situations.

- Helping behavior would differ in all the four situations depending on its intensity.

- Men would prefer helping directly whereas women would adapt an indirect way of helping.

- Married participant would prefer helping indirectly as compared to unmarried participants. 


\section{METHOD}

2.1 Participant:

Through convenience sampling, 240 people were taken out of which 120 were men and 120 women, 60 of each were married and 60 of each were single. The group included people from various socio-economic backgrounds. The ages ranged from 20 to 40 years of age. The average age of participant was 30 years.

\subsection{MATERIAL:}

One questionnaire (with 4 situations per questionnaire) was read out to each subject, the answers noted on a corresponding tally sheet. Both English and Urdu versions were provided.

\subsection{PROCEDURE:}

Research and study yielded no questionnaire for gauging levels and types of pro-social behavior. The methods previously used were based on hypothetical situations acted out but confederates for each subject, which proved to be impracticable. These methods were impractical in terms of time and finances well as pertaining to be norms of the city of Karachi which includes the high crime and harassment rates.

The sceneries were based on precious studied, a questionnaire was formulated and later tested in a pilot study to check validity. Four hypothetical situations were created each with three response choices. 4 situations were decided on because 3 or less would provide a very narrow range of options that would elicit help and would not encompass the range of situations, which would properly predict pro-social behavior. Based on rules of probability, of only 2 situations were prepared and presented, at least one would probably be beyond the realm of experience of each subject. Over 4 situations, on the other hand, would lead to boredom and fatigue, effecting responses and results.

Thus, 4 situations allow for the probability rule (where at least 3 situations would probably lie in the realm of experience of the respondent) and are also brief enough to prevent boredom and fatigue.It was also decided that each situation be kept as brief and as precise as possible. This was decided on not only to prevent boredom and fatigue but also to maintain as much clarity as possible and thereby reduce confusion and the need for extra explanations. One of the of the goals was to have each situation be as self-explanatory as possible.

Another point kept in mind while formulating the questionnaire was to use only those situations which were commonly occurring and socially acknowledged by all the classes and levels of society and which lie within the rooms of society, pertaining to Karachi. This allows the subjects to relate to each situation and given a response if not out of direct experience then from vicarious experience. The situations used where a road accident, domestic violence, female harassment and minor shoplifting. All these were more or less commonplace events

While writing each situation care was taken to use as simple vocabulary as possible to encourage ease of comprehension and (again) to have each situation as self-explanatory as possible.

Though the words and sentence construction was kept simple and direct, effort was made to make each scenario as graphically descriptive as possible within the bounds of cultural constraints. (This was especially noted in the domestic violence and female harassment situations) the goal here was to create a word picture so that visualization of each even was easy for the subjects to further ensure as natural and as real response as possible. Sound words such as 'crash' and 'thump' were used (in the domestic violence situation).

Both victims and perpetrators were humanly described such as 'young man' and 'white with shock' (in the road accidents scenario) and 'young woman' in the shoplifting scenario. All these factors added to the word picture and therefore the detailing of the image in the mind of the respondent. However it was ensured that no suggestive words or sentence were used, words which might prompt a helping response were stringently avoided to prevent an experimentation effect.

Also, while the situations were being compiled, the number of male and female victims were balanced and kept equal. This was done to prevent gender bias or at least to balance gender bias on the part of the respondent. Therefore there were 2 male victims; the accident victim and the shopkeeper (in the road accident situation and the shoplifting situation respectively) and 2 female victims; the wife and the teenage girl (in the domestic violence situation and the female harassment situation respectively).

For each situation, 3 response options were provided: response option 1 was helping directly, response option 2 was helping indirectly and response option 3 was not helping at all. In each Response Option $1 \& 2$, minor reasons for not helping were given. This was done to prevent the subject from giving a response of helping behavior out of guilt or the desire to form and maintain a positive self-image. The minor justification allowed for a more honest response. as guilt or the desire to create or maintain a positive self-image would not motivate the subject. For example in the road accident scenario Response Option $2 \& 9$ indirect help) was "you ask a man in a larger car to take him to the nearest hospital as your car will not accommodate him."

Prior to the presentation of the questionnaire to each subject, the experimenters practiced the method of reading aloud, which was to be employed. No subject was allowed to read directly from the form. Effort was 
made to ensure that reading was not done in a monotone and was as expressive as possible, with no inadvertent suggestions or prompting by word or tone. Also, each situation was to be read out as it was written without embellishment and unnecessary explanations. Voice and facial expression was to enhance the word picture only, so that it came to life as much as possible in the mind of the respondent. Each experimenter took care that voice pitch was used. Also, use of a lower voice pitch allows focus to remain on the words being spoken rather than on the voice.

Since the sample group included people from all backgrounds, an Urdu translation was made with an effort to keep as much as possible to the original content.To further reduce impact of guilt or image consciousness, the subject was not read out the word in bold print defining each response i.e. not told 'directly help', 'indirectly help' or 'walk away'.

Prior to the actual application under the experiment a pilot test was conducted to ensure validity of the questionnaire (ensure it measured what it meant to measure i.e. pro-social behavior). The results it yielded did illustrate that the questionnaire measured pro-social behavior. The results found were significant, though perhaps not reflective of the population as the sample group used in the pilot study was narrow (25 subjects).

Point were assigned on a range of 1-3,3 points were given for helping directly, 2 point were given for helping indirectly and 1 point was given for not helping. The range falling under the category of helping directly was between 10-12 points, with 12 as the highest score. The range falling under the category of helping indirectly was between 7-9. The range falling under the category of not helping was between $4-6$, with 4 as the lower score.

\subsection{Statistical Analysis:}

After the responses were collected, statistics were applied to test each of the 4 hypotheses. For the first hypothesis Chi Square was applied (Goodness of Fit). For the second hypothesis, again Chi Square was applied. T-tests were used for the third and fourth hypothesis. Two tests were applied per hypothesis, one measuring direct help and one measuring indirect help under each prevailing condition. (i.e. married vs. single and male Vs. female) Thus, in all four $\mathrm{t}$-tests were applied.

\section{Results}

TABLE 1. Path Coefficient for Helping Behavior

\begin{tabular}{|c|c|c|}
\hline \multirow{2}{*}{ Helping behavior } & $\chi^{2}$ (df) & Critical value \\
\cline { 2 - 3 } & $90.3(2)^{*}$ & 13.82 \\
\hline $\begin{array}{c}\text { Number of people who helped } \\
\text { (Directly, indirectly and } \\
\text { did nothelp) }\end{array}$ & $168.946(6)^{*}$ & 22.46 \\
\hline $\begin{array}{c}\text { Number of people who helped } \\
\text { in different situations }\end{array}$ & & \\
\hline
\end{tabular}

Notes: The sample size $(n=240)$ significance is at the 0.001 level $(* p<.01$. $)$ 
TABLE 2. Difference in Helping Behavior

\begin{tabular}{|c|c|c|c|c|c|}
\hline $\begin{array}{c}\text { Variable } \\
\text { (GROUP) }\end{array}$ & $\mathbf{N}$ & Mean & $\begin{array}{c}\text { Std. } \\
\text { Deviation }\end{array}$ & df & t-value \\
\hline $\begin{array}{l}\text { Direct Help } \\
\begin{array}{l}\text { (Male and } \\
\text { Female })\end{array}\end{array}$ & 240 & 10.483 & 10.447 & 74 & 0.237 \\
\hline $\begin{array}{l}\text { Indirect Help } \\
\text { (Male and } \\
\text { Female) }\end{array}$ & 240 & 8.288 & 8.246 & 140 & 0.333 \\
\hline $\begin{array}{l}\text { Direct Help } \\
\text { (Married and } \\
\text { Unmarried) }\end{array}$ & 240 & 10.543 & 10.390 & 74 & 1.034 \\
\hline$\frac{\text { Indirect Help }}{\frac{\text { (Married and }}{\text { Unmarried) }}}$ & 240 & 8.307 & 8.224 & 140 & 0.654 \\
\hline
\end{tabular}

Notes: The sample size $(\mathrm{n}=240)$ significance at 0.05 level $(* \mathrm{p}<0.05)$

\section{Discussion}

Our study demonstrated that helping behavior is affected in different ways depending on the situation. As it was hypothesized:

More people will help indirectly than directly and few people will not help.

On analyzing the results hypothesis has been proved to be highly significant. When the chi-square was calculated a value of $\mathbf{9 0 . 3}$ was obtained which came highly significant even at 0.001 level. Results indicated that out of total 240 subjects $\mathbf{1 4 2}$ subjects reported they would help indirectly where as $\mathbf{7 6}$ subjects choose to help directly and only 22 reported that they would not help at all.

In our culture since most of the people live in a closely-knit family system with deep cultural and religious values that are transferred from generation to generation, helping others in times of need is a core value, which is a reflection of a collectivist society. Research shows in general, a secure and emotionally warm environment seems to be beneficial for the development of pro-social dispositions. Other conditions in the socialization are modeling behavior by parents and their parenting behavior. (Eisenberg \& Fabes, 1994)

In our society children from a very young age are told to respect and love others and to treat them in the same manner they would treat one of their own. These values are based on religious teaching that if anyone is in need of help it is the duty of every person to help him or her. This is backed by a strong belief that they will be rewarded for their actions. And as noted by Thibaut \& kelley (1959) helping occurs when rewards are maximal. Therefore this belief too increases chances of helping.

While analyzing the results further it shows that of $\mathbf{7 6}$ subjects who reported that they would help directly, and was greatest in the situation involving a case of harassment. There are several reasons why most of the subjects choose to help directly. One of the main reason is that in this case the honor of the girl is at stake, and since no individual will tolerate such an act, most people reported that they would directly approach and help the girl, because if they try to go seek help from somewhere else then they would waste valuable time. Also it was found that males opted more to help directly in this situation here the personality traits of males may be an important factors, also for many males it is not just a show of strength but also a question of the "male ego". Eagly and Crowley (1986) noted that men were more likely to help if the situation was regarded as dangerous and there intervention demanded by the situation is of a direct and physical nature.

Interestingly it was seen that the highest case of indirect help was in the situation involving a case of shoplifting, where most of the subjects reported they would go to the lady (shop lifter) instead of the shop keeper to inform him about the lady's act, it was also noted that most males reported they would go up to the lady not just because of the factors of physical attractiveness, but they also felt if they would be successful enough in helping the lady to change her mind to return the stolen goods, this would help a lady to protect her honor.

Further analysis of the results indicated that $\mathbf{2 2}$ subjects reported they would not help at all, although it is only a small fraction of the sample but there is a variety of reasons as any individual trying to help some one in need lands in trouble himself, as e.g. helping an accident victim, taking him to the hospital means he would be apart of an investigation and therefore would have to face a number of problems at the hands of authority and also a lot of time will be consumed. Most subjects reported have faced this situation and had an unpleasant 
experience, which lead them to decide that even if they wished to help they would not take risk and so getting into trouble themselves.

However interestingly the highest number of people who reported not to help was in the situation depicting a scene of domestic violence, where most of the subjects reported saying that it is a private matter and they would not like to interfere. Also in Pakistani society generally a man beating a woman (wife) is considered normal and often if a wife reports being abused, she is told to accept it as a part of her marital life. Interestingly in many cases even the wife herself does not like interference of any one in her personal life. Most of our subjects reported that they would not help in such a situation, because they did not interpret the situation as an emergency. Guenther et. al (1986) noted that there are many reasons why people chose not to help in a situation. One explanation for people being reluctant to help is because different people define situations in different ways. Some may see an emergency and some may look right over the situation and label it as insufficient in terms of help required.

If another women tries to intervene and help, it may cause problems for the women mainly because women are weak and lack the strength to stand up and fight for the rights of another women, especially if they are just a house wife and not in a position of authority, what normally happens is that the man may go up to the women's husband and inform him of her actions which may make the situation worse for the women herself who was just trying to help another women in need. It is for these reasons that most of the subjects reported they would not help.

\section{The hypothesis that helping behavior would differ from situation to situation was proved to be significant when chi-square was calculated.}

If we analyze the situations we see that there was a vast difference between the helping behavior of all the 4 situations. The least help was for the $2^{\text {nd }}$ situation in which domestic violence had been portrayed. Out of 240 participants, only 62 opted for direct help, where as 46 opted for indirect help. More than half i.e. 132 participants of the survey said that they would not interfere in the situation. The reasons that participants gave for not helping in this situation were that they thought that it was a personal matter $\&$ they should not interfere. Such kind of domestic life is very common in our society \& it is not considered to be wrong for the husband to abuse his wife. The situation may be considered to be ambiguous \& the neighbors may not consider it to be such that requires help.

Other reasons that participants gave for not helping in this situation was apart there taken it as a family matter. Even women of this society do not like to expose this fact in public as their spouse is "sacred" for them. Ups \& downs in marital relationships are a part of every day life. Subjects responded that if they would go \& help the abuse, the husband who is already in an a violent mood would show his aggression towards the helpers, Maybe he would take his neighbours as the females specially reported that if they try to help in any case they would be unable to handle the aggression of a man $\&$ another reason if the man would in return complain about her to her husband leading to create problems for her also. An interesting factor was that most participants who belonged to lower socio-economic class responded that they would help directly in all situations even in the one, which was about domestic violence. The reason was that they live in closely knit groups \& help each other in all occasions, because if they would not help them in return, their neighbors would also not help them in time of need. Research in cities of various sizes shows that people who live in small communities are more likely to help (Levine et. al 1994). Research has also documented the obvious, namely, that a warm, friendly community or environment encourage more helping responses than a cold, suspicious, punitive situation. If the situation poses some danger-like intervening in a family fight-we are less likely to offer help.

It was seen that the most direct help was offered in the $3^{\text {rd }}$ situation concerning molestation. 136 participants opted for direct help, 85 opted for indirect help \& only 19 responded that they would not help at all out of these majority were females i.e. 12 , which means that only 7 were males. It was noted that even females opted for helping in this situation indirectly if not direct. According to Latane \& Darley (1976) whether a person takes direct action or seeks further assistance from someone else depends on many factors such as the type of aid needed and the expertise of the potential helper.

The severity of this situation was high as there were chances that the girl would get raped or kidnapped. In our society, often we see in shopping areas \& market places, if a woman is harassed \& calls out for help then there are a number of male members who would come to her help. It is a question of honor for males $\&$ they cannot bear any woman being molestated in front of their eyes \& they would be doing nothing to help. Social values are thought of as stable disposition with which individuals enter a choice situation (Van Lange \& Liebrand, 1991). The number of female indirect helper was high in this case i.e., 57 females reported that they would ask someone to help the victim or call the police because they were afraid that the molester would attack them instead \& more over they were not competent enough to face the situation. Research supports the fact that females of this period have a more liberal thinking \& they are competing with the men in all walks of life. They may be physically weak but they would try their level best to help female victims or at least they think that they 
will help! Research supports the fact that females help because of their empathetic nature. Females have been found to be significantly more altruistic and empathic (and less aggressive) than males, and altruism had been found to increase with age from 20 to 60, while aggression decreased (N.C. Higgins \& Joanne K. Shaw, 1999).

Shotland \& Huston (1979) attempted to determine what characteristics of a situation make people consider them emergencies if they: 1) Occurs suddenly \& un expectedly, 2) Involving threat of harm or actual harm to be victim, 3) Grow increasingly with time, 4) Render the victim helpless, 4) Allow for potentially effective intervention.

We see that the situation of molestation as well as of an accident were severe in nature therefore more people were likely to intervene in them.

Interestingly it was noted that unlike the molestation situation, there were quite many people (55) who opted that they would not help in the accident situation. The participant gave the reason that that in Pakistan, people who help an accident victim were often taken as an accused by the police. Moreover the helper is suppose first to lodge an FIR (first investigative report), and then only the hospital takes the case for emergency. It is common that at least once in a lifetime we have seen an accident take place in front of our eyes but above mentioned issues lead us to walk away from the situation. As it was specified in our accident situation that there were quite a few people who were preceding to the accident spot, we can say that more people when present, the less likely any one person is to help because of the bystander effect.

An equal number of subjects reported that they would ask someone else to take the accident victim probably because they wanted to help in the serious situation but were afraid to encounter problems with the police or found the situation very threatening, therefore they helped indirectly. People who help indirectly feel guilty if they do not help at all.

In the situation in which the female has been portrayed to be stealing from a shop, 92 people responded that they would help directly, 98 responded that they would help indirectly \& 50 responded that they would not help at all. These results are really interesting as although the amount of threat involved is very low, yet people opted that they would help indirectly. The reason participants gave was that they would ask the woman to return the stolen perfume bottles (in direct help) because otherwise it would create a scene. Another important finding was that 57 males responded that they would ask the woman to return the bottles where as 38 said that they would tell the shopkeeper of his shop being robbed. The gender of the person being helped is an important factor in helping behavior because men and women may be more willing to help a person of the opposite sex (Benson, et al., 1976). More male helpers opted for indirect help because it meant having interaction with the female \& men are always in search of interacting with the opposite sex \& portray themselves positively in front of them. On the other hand more females reported that they would help directly probably because they were more concerned of saving the items being stolen rather then interacting with the woman who would probably get away with it. Telling the shop keeper of the theft would mean that the shopkeeper would himself catch the woman red handed or ask one of his salesmen to do so before the woman would get away with it.

For the analyses of variables of the married and unmarried people under the independent variable of helping behavior, $t$-tests were applied.

One of these measured the difference between direct helping by the 2 groups. The hypothesis stated that married people are more likely to help indirectly while unmarried people are more likely to help directly. It was found that the difference between the helping behavior of the 2 groups was not significant both under direct helping behavior ( $\mathrm{t}=1.034)$ and indirect helping behavior $(\mathrm{t}=0.656)$, the significance level at $\mathrm{p}>0.05$. (Refer to Table). The experimental hypothesis was therefore rejected and the null hypothesis was accepted. Both groups showed approximately the same levels of pro-social behavior, whether direct or indirect.

The main reason for this is speculated to be the strong cultural norms associated with social responsibility and awareness. These exist and are strongly reinforced within the Pakistani society and in most of the cultures in the Asian region, including India and China and are stronger here than in most American and European societies. Latanè \& Darley (1969) found that if the victim is perceived similar to oneself there is a higher level of helping and that observation of helpful models also increases the likelihood of helping, both of which have an effect on helping behavior regardless of marital status, Karachi has a large middle class, spanning from lower middle to upper middle within that range. Therefore there is a higher probability of victims being similar to oneself, on the grounds of social class and socio-economic status. This perception of similarity is a strong influencing factor as the helper then relates to the victim, which increases helping behavior. Also, based on cultural factors and the existence of a close family unit is it highly likely that the helper has witnessed a number of helpful models. Unlike in the West, family (and therefore, models) are not confined to the immediate family but include extended family as well increasing the available pro-social models.

This influences helping behavior regardless of marital status, as these models existed pre-marriage as well as post marriage. 
Another fact which lead to these results is that marriage probably increases an individuals sense of empathy, understanding and responsibility, therefore shifting their stance toward helping behavior whether direct or indirect. Young unmarried people, on the other hand help on an approximately equal scale but for different reasons, usually a stronger parental and familiar influence couple with youth's impetuosity and verve. Therefore the helping behaviors of the 2 groups will be approximately the same though different motivating factors exist for them.

The final factors, which will motivate helping behavior, regardless of marital status, is the presence of strong religious beliefs and training. The religious socialization in Karachi is obviously a strong existing phenomenon. Religious norms include helping others, with the motivation of pleasing God. Therefore all other factors become less pronounced and the religious conditioning motivates the individuals to help, regardless of environmental conditions or martial state.

Therefore it can be seen that helping behavior is less influenced by marital status and more by the existing social factors and religious conditioning that prevail in the Karachi society. This is probably why the helping behavior of the 2 groups is approximately on the same level.

\section{This hypothesis that males will help directly $\&$ females will help in directly was not proved. Significant difference was not found.}

Despite the fact that men and women tend to place different values on altruistic acts, Krebs (1970) found that there were no gender differences in the actual performance of helping behaviors. Similarly, Chou (1998) examined the affect of gender and participation in volunteer activities on altruistic behaviors. The study found that there was a positive effect of age on altruistic behavior- the older the adolescent, the greater was their score for prosocial behavior. However, there was no gender difference for the frequency of helping behaviors.

Pandey and Griffitt (1977) contend that, on the basis of studies investigating sex differences in altruism, it cannot be concluded that one sex is consistently more helpful than another. Depending on the nature of the experiment, men have been demonstrated to have a higher degree of displayed helpfulness.

Eisenberg, et al. (2006) pointed out that "based on stereotypical gender roles, females generally are expected and believed to be more responsive, empathetic, and prosocial than males, whereas males are expected to be relatively independent and achievement oriented". Other than this acknowledgement of gender stereotypes in altruistic situations, studies conducted on the perceptions of gender on altruistic behaviors are minimal. Such studies mostly involve children's perceptions about gender and the role of gender in altruistic acts. The research has consistently found that, when children are asked who is more altruistic, girls are generally rated as more altruistic than boys; this perception also exists in teachers (Shigetomi, Hartmann, \& Gelfand, 1981).

Further research on children's perceptions of gender in altruistic situations has explored the possibility that this impression that girls are more altruistic may be due to a measurement bias (Zarbatany, Hartmann, Gelfand, \& Vinciguerra, 1985).

There are several reasons that indicate that there is no significant difference between the helping behavior of males \& females. The situations that were formulated were all hypothetical whereas real situations that could predict helping behavior were not demonstrated. Participants reported that they would intervene with the situation but the results in actual situations might be different. Helping situations characterized by such different aspects as a high number of other potential helpers (the 'bystander-effect'), bad weather conditions, a high population density, a bad mood of the potential helper, an unattractive physical appearance of the person in need of help, a dissimilarity between the beneficiary and the benefactor, an indirect and ambiguous request for help and time pressure felt by the beneficiary, all have been shown to lead to lower rates of helping behavior (Schroeder, Penner, Dovidio \& Piliavin, 1995). Therefore we can relate to this factor that males as well as females responded positively as they thought they would help as they were not able to analyze the risks \& dangers involved in the situations \& were also unable to consider factors like weather \& mood etc.

In our survey, it was noted that helping behavior amongst males \& females differed from situation to situation. In the first \& the third situation where physical help was needed \& where risk factors were involved more as compared to the other two situations, it was noted that males helped directly while females helped indirectly. 70 males opted to help directly in the first situations whereas 60 females opted for indirectly help. In the $3^{\text {rd }}$ situation this difference was more obvious. 87 males responded to help directly whereas 49 females responded to help directly. In direct help was more prevalent amongst females in the $3^{\text {rd }}$ situation i.e., when females could not help directly due to their physical weakness, they tried to help the victim indirectly. In other situations the difference in direct/indirect help was not very obvious because the situations did not include physical threat.

Pandey and Griffitt (1977) contend that, on the basis of studies investigating sex difference in altruism, it cannot be concluded that one sex is consistently more helpful than another. Depending on the nature of the experiment, men have been demonstrated to have a higher degree of displayed helpfulness. 1) Male "heroic" role encourages helping when: a) The intervention is dangerous, b) An audience is present, c) Other helpers are 
available, d) The encounter is short-term and the victim is a stranger. 2) Female "nuturant" role encourages helping when: a) Close relationship not strangers, b) Long-term care is required.

If we consider the above factors, we are likely to interpret that females would be more helpful when the neighbor is facing domestic violence but our research does not support this factor because of our cultural \& social factors. Whether it is a male or female, people refuse to help when domestic violence is involved as they consider it a personal family matter.

The gender of the person being helped is an important factor in helping behavior because men and women may be more willing to help a person of the opposite sex (Basow \& Crawley, 1982) furthermore, the attractiveness of the person being helped can influence the willingness to help, especially for male helpers (Benson, et al., 1976; Harris \& Bays, 1973). An interesting finding was that in our $4^{\text {th }}$ situation in which a female is portrayed to be stealing from a shop, the victim was a male (the shop keeper) yet most males in this situation were more likely to opt for the choice of going up to the female $\&$ telling her to return the stolen items rather then going to the shop keeper to complain. This is a pure indicator that as the thief was a female; the males were likely to go to the opposite sex person rather than helping then helping directly.

In a study by (West, et al., 1975), A motorist (actually a confederate) stood by a immobilized car at the side of a busy thoroughfare. Male motorists were likely to stop \& help than female motorists. Further more, motorists were likely to stop if the victim was a female. The fact that female victims were more often helped may stem from a general conception that females are less capable of repairing cars, \& perceived competence of their perception that they are less competent to help in this situation or their greater fear of stopping, particularly for a male motorist.

To put it in a nutshell, the sex of the victim is an important factor to determine if she/he will receive help or not \& whether he/she will be helped by males or females. Therefore we can conclude that as we had mixed kind of situations in which males \& females were both victims \& the demand of each situation varied from the other; therefore the difference between the helping behavior for males \& females was not significant.

\section{RECOMMENDATIONS}

* All the situations used in this survey were hypothetical and therefore the answers that we received were also accordingly, if the situations were demonstrated practically then the answers would be more realistic.

* Since this survey had situations read out to people it became more like a measure of attitudes rather than their behavior.

* The use of 'Indicators' about their past life concerning similar situations would have been a better predictor of the authenticity of their responses.

\section{References}

[1] Baron, R. (1997). The sweet smell of...helping: Effects of pleasant ambient fragrance on pro-social behavior in shopping malls. Personality and Social Psychology Bulletin, 23(5), 498-503.

[2] Batson, C. Daniel (1998). Altruism and Pro-social Behavior. Ch. 23 in Handbook of Social Psychology, $3^{\text {rd }}$ Edition, New York; Random House. pg. 282-316.

[3] Batson, D., \& Schoenrade, P., \& Ventis, L. (1993). Religion and the Individual. New York: Oxford University Press.

[4] Batson, Daniel C (1991). "The Altruism Question" Lawrence Erlbaum Associates, Publishers New Jersey.

[5] Benson, P.L., Karabenick, S.A., \& Lerner, R.M. (1976). Pretty pleases: The effect of physical attractiveness, race and sex on receiving help. Journal of Experimental Social Psychology, 12, 409-415.

[6] Bihm, E., Gaudet, I., \& Sale, O. (1979). Altruistic responses under conditions of anonymity. Journal of Social Psychology, 109, 2530 .

[7] Boice, K., \& Goldman, M. (1981) Helping Behavior as affect by type of request and identity of caller. The Journal of Social Psychology. 115, 95-101.

[8] Chou, K. (1998). Effects of age, gender, and participation in volunteer activities on the altruistic behavior of Chinese adolescents. The Journal of Genetic Psychology, 159, 195-201

[9] Clary, E.Gil \& Miller, Jude (1986). Socialization and Situational Influences on Sustained Altruism. Child Development, 57: 13581369.

[10] Cohen, R. (1972) "Altruism: Human Control or What? Journal of Social Issues, Vol. 28, pg. 28.

[11] Colaizzi, A., Williams, K.J., and Wesley, A.K.(1984). When will people help? The effects of gender, urgency, and location on altruism. Psychological Reports.

[12] Cramer, R.E., McMaster, M.R., Bartell, P.A., \& Dragna, M. (1988). Subject competence and minimization of the bystander effect. Journal of Applied Social Psychology, 18(13), 1133-1148.

[13] Cunningham, M. (1979). Weather, mood, and helping behavior: Quasi experiments with the sunshine samaritan. Journal of Personality and Social Psychology, 37(11), 1947-1956

[14] DA, Clark RD III. 1991. The Arousal: CostReward Model and the process of intervention: a review of the evidence. See Clark 1991, pp. 86-118

[15] Darley, J.M \& Latane, B (1968) "Bystanders Intervention in Emergencies, Diffusion of Responsibility. Journal of Personality and Social Psychology. 8:377-383.

[16] Dougherty, C.W. (1983). Distraction and sex role as determinant of compliance with a request for help. Journal of Social Psychology, 119, 31-36. 
[17] Dovidio, J.F., Piliavin, J.A., Gaertner, S.L., Schroeder, D.A., \& Clark, R.D. (1991). The arousal: Cost-reward model and the process of intervention: A review of the evidence. In M.S. Clark (Ed.), Prosocial behavior (Review of Personality and Social Psychology, No. 12). Newbury Park: Sage Publications, pp. 843-853

[18] Durkin, Kevin. (1995). Developmental Social Psychology: from infancy to old age. Cambridge, Mass.: Blackwell.

[19] Eagly, A. H., \& Crowley, M. (1986). Gender and helping behavior: A meta-analytic review of the social psychological literature. Psychological Bulletin, 100, 283-308

[20] Eisenberg, N., \& Fabes, R.A (1994) Mother's Reaction to Children's negative emotions: Relations to Children temperament \& anger behavior. Merrill-Palmer Quartely; 40,138-156.

[21] Eisenberg, N., Fabes, R., \& Spinrad, T. (2006). Prosocial Development. In N. Eisenberg, W. Damon, \& R. Lerner (Eds.), Handbook of child psychology: Vol. 3. Social, emotional and personality development (6th ed., pp.646-718). Hoboken, NJ: John Wiley \& Sons.

[22] Eisenberg, Nancy \& Miller, Paul A. (1987). The relation of empathy to pro-social and related behaviors. Psychological Bulletin, 101, 91-119.

[23] Feinman, S. (1978), 'When Does Sex Affect Altruistic Behaviour?', Psychological Reports, 43: 12-18.

[24] Froming, William J \& Nasby, William \& McManus, John. (1998) Pro-social self-schemas, self-awareness, and children's pro-social behavior. Journal of Personality \& Social Psychology, 75(3), 766-777.

[25] Goldman, M., \& Fordyce, J. (1983). Prosocial behavior as affected by eye contact, touch, and voice expression. Journal of Social Psychology, 121(1), 125-129.

[26] Goldstein, Amold P. (1985). Empathy: development, training and consequences, Hillsdale, N.J.: L. Erlbaum Associates

[27] Guéguen, N., \& De Gail, M. (2003). The effect of smiling on helping behavior: Smiling and good Samaritan behavior. Communication Reports, 16(2), 133-140.

[28] Harris, M.B., \& Bays, G. (1973). Altruism and sex roles. Psychological Reports, 32, 1002.

[29] Hart, Daniel \& Fegley, Suzanne. (1995) Pro-social behavior and caring in adolescence: Relations to Self-Understanding and Social Judgment. Child Development, 66(5), 1346-1359.

[30] Hilgard. R. Ernest, "Introduction of Psychology" $8^{\text {th }}$ Edition HBJ publishers.

[31] Hoffman, Martin L. "Is Altruism a part of human nature?" Journal of Personality and Social Psychology. Vol. 40, 1981. pg. 121.

[32] Karakashian, L., Walter, M., Christopher, A., \& Lucas, T. (2006). Fear of negative evaluation affects helping behavior: The bystander effect revisited. North American Journal of Psychology, 8(1), 13-32. Ganser, Huda UW-L Journal of Undergraduate Research XIII (2010)

[33] Kassin, S., Fein, S., \& Markus, H. R. (2008). Helping others. In Social psychology (pp. 344-386). Boston: Houghton Mifflin Company.

[34] Kelley Guenther, James Lesniak, Angela Magnuson, \& Kelly Underwood.(1986). Helping Behavior: Altruism on the Far Side. Journal of Social Psychology.psy:324.

[35] Krebs, D. L. Altruism: An examination of the concept and a review of the literature. Psychological Bulletin, 1970, 73, 258-302

[36] Kunstman, J., \& Plant, E. (2008). Racing to help: Racial bias in high emergency helping situations. Journal of Personality and Social Psychology, 8(4), 377-383.

[37] Latané, B. \& Darley, J.M. (1970). The unresponsive bystander: Why doesn't he help? New York: Meredith Corporation.

[38] Latane, B., \& Darley, J. M.(1976). Help in a crisis: Bystander response to an emergency. Morristown, N.J.: General Learning Press.

[39] Latane, B. \& Darley, J.M. (1969). Social determinants of bystander intervention in emergencies. In J. Macaulay \& L. Berkowitz (Ed s.), Altruism and Helping (pp. 13-27). New York: Academic Press.

[40] Levine, M., \& Crowther, S. (2008). The responsive bystander: How social group membership and group size can encourage as well as inhibit bystander intervention. Journal of Personality and Social Psychology, 95(6), 1429-1439.

[41] Levine, R., Martinez, T., Brase, G., \& Sorenson, K. (1994). Helping in 36 U.S. Cities. Journal of Personality and Social Psychology, 67, 69-81.

[42] Myers. G.David: "Psychology", Worth publishers Inc, 1992.

[43] N.C. Higgins \& Joanne K. Shaw (1999): Attributional style moderates the impact of causal controllability information on helping behaviour. Social Behavior and Personality, 27(3), 221-236.

[44] Natale, Samuel, (1972). An Experiment in Empathy. Slough; National Foundation for Educational Research In England and Wales.

[45] NORC General Survey (1996) Conduct by National Opinion Research center.

[46] Pandey, J., \& Griffitt, W. (1977). Benefactor's sex and nurturance need, recipient's dependency, and the effect of number of potential helpers on helping behavior. Journal of Personality, 45, 79-99.

[47] Perlow L, Weeks J. 2002. Who's helping whom? Layers of culture and workplace behavior. J. Organ. Behav. 23:345-61.

[48] Piliavin, J.A., Dovidio, J., Gaertner, S., \& Clark, R.D.(1982) Responsive Bystander: The process of intervention. In V.D erlega \& J. Grezelak (eds), Cooperation \& Helping Behavior: Theories and research. NY Academic Press.

[49] Roberts, William \& Strayer, Janet, (1996). Empathy, emotional expressiveness, and pro-social behavior, Vol. 67(2), 449-470.

[50] Schroeder DA, Penner LA, Dovidio JF, Piliavin JA. (1995). The Psychology of Helping and Altruism. New York: McGraw-Hill.

[51] Schroeder, D.A. \& Clark, R.D. (1991) The arousal cost-reward model and the process of intervention in M.s. Clark (eds) Review of Personality \& Social Psychology. Vol,12: Prosocial Behavior. Newbury Pak C.A.Sage.

[52] Shigetomi, C., Hartmann, D. P., \& Gelfand, D. M. (1981). Sex differences in children's reputations for helpfulness. Developmental Psychology, 17, 434-437.

[53] Shotland, R. L. \& Huston, T.L. (1979). Emergencies. What are they and do they influence bystanders to intervene? Journal of Personality and Social Psychology, 37, 1822-1834.

[54] Stang, D.J., \& Wrightsman, L.S.(1981) A dictionary of social behavior and social research methods. Monterey, CA: Brooks/Cole.

[55] Strom, S. (2006, June 19). Report finds disasters fueled rise in giving in 2005. New York Times.

[56] Thibaut, J. W. and Kelley, H. H. (1959) The social Psychology of Groups, New York: Wiley Third, Hamilton and Stewart (1993)

[57] Van Lange, P. A. M., \& Liebrand, W. B. G. (1991). Social value orientation and intelligence: A test of the goal prescribes rationality principle. European Journal of Social Psychology, 21, 273-292

[58] West, Stephen G., Glayde Whitney, \& Robert Schnedler. (1975) "Helping a Motorist in Distress: The effects of Sex, Race and Neighbourhood." Journal of personality and Social Psychology 31:691-98.

[59] Wilson, E.O., (1978). On Human Nature. Massachusetts: Harvard University Press.

[60] Zarbatany, L., Hartmann, D., Gelfand, D., \& Vinciguerra, P. (1985). Gender differences in altruistic reputation: are they artifactual? Developmental Psychology, 21, 97-101. 